\title{
Quantifying the extraction of art meaning: no laterality effect
}

Jose Luis Vilchez, Wendy Lizbeth Michay Valarezo

Universidad de Cuenca, Ecuador

Neuropsychiatria i Neuropsychologia 2020; 15, 3-4: 101-107

\author{
Address for correspondence: \\ Jose Luis Vilchez, PhD \\ Facultad de Psicología \\ Universidad de Cuenca \\ Av. 12 de Abril \& Av. Loja \\ Cuenca, Azuay, Ecuador \\ e-mail: jlvil@hotmail.de
}

\section{Abstract}

Introduction: The present study investigates the differential evaluation, motivational preference and ideomotor action (decision making) of Psychology students over pieces of graphical art.

Material and methods: Abstract and figurative art pictures were presented in two different visual hemifields in a decision task to 31 Psychology students. There were 90 trials in which participants had to make this decision/ preference.

Results: The findings indicate that there is no laterality effect in the two dependent variables used: count of preferences and response times (RTs). This statement is based on the fact that there is no interaction effect of more preferences or longer RTs depending on the side where the decision task was presented. On the other hand, there is a preference effect in the sense that the participants chose significantly more times the figurative art than the abstract one. In this sense, when preferring abstract art, participants spend significantly longer RTs than when they preferred figurative art.

Conclusions: The results suggest that, for high level cognitive processes (such as paying attention and making decisions with art; in comparison to the plain perception and evaluation of it), there is no laterality effect. This conclusion is based on the lack of interaction effect depending on the side/hemifield where the decision task was presented. Moreover, Psychology students make a more analytical analysis of art since they prefer figurative art over abstract art. Finally, we can quantify the time that participants spent in extracting abstract art meaning, since they spent (as a mean) $231.78 \mathrm{~ms}$ longer when preferring abstract art than when they preferred figurative art.

Key words: abstract art, figurative art, no laterality effect, analytical analysis, art meaning.

\section{Introduction}

Hegel (1997) proposes that art is a particular form of expression through which human beings manifest themselves. In this sense, art aims to transmit the ideas behind art itself and to make them accessible to our metacognitive processes. This natural manifestation - which implies imagination, creativity and technique - all together brings us directly to the human essence.

Art excites the cognitive system, including emotion, but collaterally, since this consequence is not its primary aim (Dickie 2005). In order to make predictions about emotional reactions in respond to art, two concepts must be taken into account: the collative variables and the arousal model of reward (Berlyne 1966). On the one hand, collative variables are the structural features (semantic primitives; in terms of God- dard and Wierzbicka 1994) embodied in art that make every piece of this manifestation idiosyncratic. In this sense, paintings, music, literature, or films could be described as particular creations that differ in complexity, novelty, uncertainty, or conflict of these variables (Moles 1966). On the other hand, if art is understood in terms of objective stimulus features, such as complexity or novelty of semantic primitives, then emotional responses to art can be explained based on the hedonic effects for the specific configuration of collective variables (Berlyne 1957, 1960). Berlyne (1971) proposes that the quantitative and qualitative differences between the properties of the perceived object and the characteristics of the reference model of this kind of object govern aesthetic appreciation.

This difference constitutes the base of the socalled arousal potential which triggers emotion. 
As a result, preferences, motivation, and the feelings generated from art can be understood in terms of how the collative properties, inserted in it, can affect the arousal systems of reward.

\section{Neural bases of art and emotion}

Regarding the biopsychology of art and emotion, literature indicates that the cerebral hemispheres are specialized to carry out diverse, cognitive functions, although this specialization is not holistic (Damasio 1994; Davidson 1992). In the neural systems, neural nuclei coordinate themselves to underlie and support cognitive processes: functional systems (in term of Luria 1966). In this sense, many functions of our mind are not equally distributed between left and right hemispheres. The hemispheres are specialized in different information processing and are mutually coordinated to carry out specific, mental tasks. In this regard, in order to process determined information, one of the two cerebral hemispheres is more active. For example, on the one hand, the left hemisphere is more specialized in processing verbal material. On the other hand, the right hemisphere is in charge of visuospatial tasks regarding the relationships between forms, distance and space (Hernández Belver 1990).

Traditionally, the right hemisphere is considered involved in the emotional aspects that are transmitted through language, which are involved in the verbal description of an emotion (Martínez et al. 2011). The right hemisphere is also related to the emotional aspects that are transmitted through gestural expressions, processing information with emotional connotations. In this sense, evidence shows that the lower right frontal cortex is related to the asymmetrical processing of emotional signals, both visual and acoustic (Damasio 1994), having an important role in the perception and interpretation of emotional intonation (Panksepp 1998).

According to Peretz and Zatorre (2005), there is a dissociation in the right and left hemispheres of the brain not only in the perception of emotions but in the evaluation of pieces of pleasant and unpleasant musical art. In this sense, when using musical stimuli, tonal melodies were found more pleasant when processed in the left hemisphere, whereas atonal melodies were found more unpleasant when processed in the right hemisphere (Peretz et al. 1998). The predominant activation of the left hemisphere involves the fronto-temporal lobe regarding positive emo- tions (and more related to personal experiences), such as joy and happiness, and the predominant activation of the right hemisphere is located in these same areas but with negative emotions such fear or sadness (Schmidt and Trainor 2001), revealing a bilateral but specialized activation (a different one for each emotion depending of the value of that emotion). In particular, these specific areas (within the frontal-temporal lobes) seem to be more involved in emotional evaluation and judgment rather than the plain perceptual analysis of emotional information (Heilman 1997). On the other hand, the anterior cingulate cortex (ACC) is more bilaterally active when the participants have to not only perceive and evaluate, but also pay attention and make a decision about the music they are listening to (Bush et al. 2000), in this case, independently of the value of the emotion. This point is crucial for our study.

\section{Processing style of both hemispheres}

Levy (1974) demonstrated that the hemispheres have different styles of processing information. The left hemisphere processes information in a more conceptual, analytical, and sequential manner, which is optimal for carrying out language functions. Meanwhile, the right hemisphere has a more synthetic and simultaneous operating mode, given its visuospatial capacity. According to Delgado (1994), the left hemisphere is dominant in performing logical-analytical functions. The left areas of the brain have greater presence in the control over elements, such as with manual skills, reading tasks and the understanding of words. However, the right hemisphere is more related to spatial sensitivity, emotions, imagination, art and nonverbal information.

Some of these differences in the way of processing information have been analyzed in the comparison between students of Fine Arts and students of Psychology, by using tests of cerebral laterality in the perception of art (Hernández Belver 1990). These studies show the predominance of the right hemisphere in the students of Fine Arts in appreciating artworks. For the students of Psychology, there was a greater predominance of the left hemisphere during the same task. The possible explanation of these results is that individuals most related to the art perform a visual analysis on a different level (more emotional and holistic) than the participants who do not belong to this area of knowledge (more 
analytical and based on the collective variables inserted in art).

In this sense, in those subjects with left hemisphere predominance (in this case, students of Psychology), there seems to be a deeper, critical analysis of the semantic content regarding the information concerning art. This finding has been related to the fact that the left hemisphere is responsible for language processing (Hernández Belver 1990). This innate ordering of the semiotic information of the reality that surrounds us (and, therefore, the sequencing of the concepts) that the subject performs instinctively is called generative grammar (in terms of Chomsky 1980).

This "grammar" includes the different rules that facilitate the process of generating the linguistic expressions of language. This working mode can also be extrapolated to other situations that occur in nature. This mental process is independent of the content or material being processed.

\section{The perception, attention and reaction to the content of art}

Regarding the content of art, prior experience of subjects modulates the perception and preference for an abstract or figurative artistic style. Hence, an individual who is immersed in the artistic field reacts differently than someone who has not had that level of contact with this area. This difference in the manner of processing is based on the "specialized" mental representations that the artists have. The distinctive nature of the pieces of art makes artists able to understand and appreciate elements that are not in the scene itself [only in its a priori synthesis; in terms of Kant (1787/1948)].

The perception and reasoning of artists come along with the way of conceiving their environment and expressing their feelings; it would be the accumulation of mental footnotes [in terms of Vilchez $(2016,2018,2019)$ ], which gives idiosyncratic meanings to their world (the ones that are more related to personal experiences; Schmidt and Trainor 2001). To this aim, the cognitive process of appreciation of art uses previous elements from sensory, motor and affective experiences (Tiso 1990).

For Gestalt Psychology, objects provide certain information referring to their own structure through their contours. The subject also contributes to the perceived object and there are certain laws that govern the process of his/ her perception (Katz 1967). In this sense, after perception, affective action and decision effects have directive and incentive functions for action control. As anticipated sensory consequences, they can be used to select and initiate a behavior that produces the anticipated effect, even when the outcome has aversive properties. This ideomotor process allows for a volitional control of action (preference), relating emotion with motivation. As anticipated hedonic consequences, they can be used to selectively enhance behaviors that generate pleasant and desired effects, controlling behaviors that are in the service of the individual's needs and desires. The outcome is a dynamic action regulation in which behavioral tendencies evoked by ideomotor and motivational processes mutually support or constrain each other in the control of instrumental action (the decision of preference itself; Eder et al. 2014).

\section{Aim of the study}

Literature shows a dissociation in the right and left hemispheres of the brain in the perception of musical art (Peretz and Zatorre 2005) but there is not this laterality in the attention to art and the decision making about it (Bush et al. 2000). On the other hand, it can also be found that students of Fine Arts and students of Psychology differ in the analysis of art (Hernández Belver 1990), the students of Psychology being the ones who analyze art in a more conceptual, analytical, and sequential manner (Chomsky 1980). Furthermore, it is taken into account that the definition of abstract art is the one that does not represent recognizable scenes or objects and figurative art is the one that imitates nature (Read 1948). Therefore, the present study investigates the differential evaluation, motivational preference and ideomotor action (decision making; Eder et al. 2014) of Psychology students over pieces of graphical art.

First of all, the main hypothesis is that, since the ACC is bilaterally active when the participants have to pay attention and make a decision about art (Bush et al. 2000), there will be no laterality effects on the preference for the two kinds of art. That is to say, the different kinds of art may trigger different emotions but there will be no laterality effects on the preference shown by Psychology students. Therefore, there will be no differences if, in the decision task, the abstract art is presented on the right, visual hemifield and the figurative art on the left, visual hemifield (compared when the abstract art is presented in the right hemifield and the figurative art in the left hemifield). 
Secondly, given the differences found in students of Fine Arts and students of Psychology regarding their processing of art (Hernández Belver 1990), by using Psychology students, we assume they will be more analytical (given their higher activation of the left hemisphere in the perception of art) and they will prefer the figurative art (since its collative variables are easier of be analyzed) over the abstract art.

Thirdly, since abstract art does not represent recognizable scenes or objects (Read 1948), the meaning that abstract art has is supposed to be harder to extract than the figurative one. For this assumption, the differential number of collative variables between figurative and abstract art and the more difficult comparison of them with their (although unknown) model of reference (Berlyne 1966) are taken into account. Therefore, the response times (RTs) in a preference/decision task about these two kinds of art will be longer for abstract art than for figurative art.

\section{Material and methods}

\section{Participants}

Thirty-one university students aged 18-28 years $(\mathrm{M}=20.52, \mathrm{SD}=2.42,21$ females $)$ participated in this experiment. All participants reported normal or corrected-to-normal vision and hearing, and were naive to the purpose of the experiment. All of them provided informed consent for their participation and received no kind of reward.

\section{Stimuli}

Fifteen abstract images and 15 figurative images were used for this experiment (see Fig. 1 as example, in which the images have been degraded for copyright reasons). We obtained the images from the internet by using the "Google search engine" (Google LLC) and by using in Spanish the concepts of "abstract art" and "figurative art". We suppose that the results firstly ordered in this search represent better the concepts of both kinds of pictures. These images were selected with the criteria of: A) being the first to appear in the results, B) not being already selected. When the picture was horizontal, the dimension was standardized in width for every image (400 pixels wide/ $45 \mathrm{~cm}$ when projected on a screen), and the height was kept proportional to the original width in every case. When vertical, the standardization was made the other way around.

In every presentation, two images (one abstract and the other figurative) appeared at the same time. The restriction took place in the combination of these images. In this sense, when a random abstract image appeared on the left of the screen, a figurative image appeared on the right and vice versa.

\section{Procedure and materials}

Once participants were seated comfortably (and after having accepted the informed consent form), they were given the instructions of the task. The instructions specified the necessity of deciding between the two images that were projected on the screen. In every single trial, participants had to evaluate whether they preferred the abstract or the figurative images paired two by two. The block of trials consisted of 90 randomized trials (extracted from a pool of 450 images) without repeating any trial. Taking into account that the distance in which participants were seated from the screen was $140 \mathrm{~cm}$, the width of the projected images was $30 / 45 \mathrm{~cm}$ and the high of the images was $30 / 45 \mathrm{~cm}$ (depending on whether the pictures were vertically or horizontally formatted), this would make a maximum of $0.42 / 0.62$ visual angles for the $30 / 45 \mathrm{~cm}$ of each vertical or horizontal projected image.
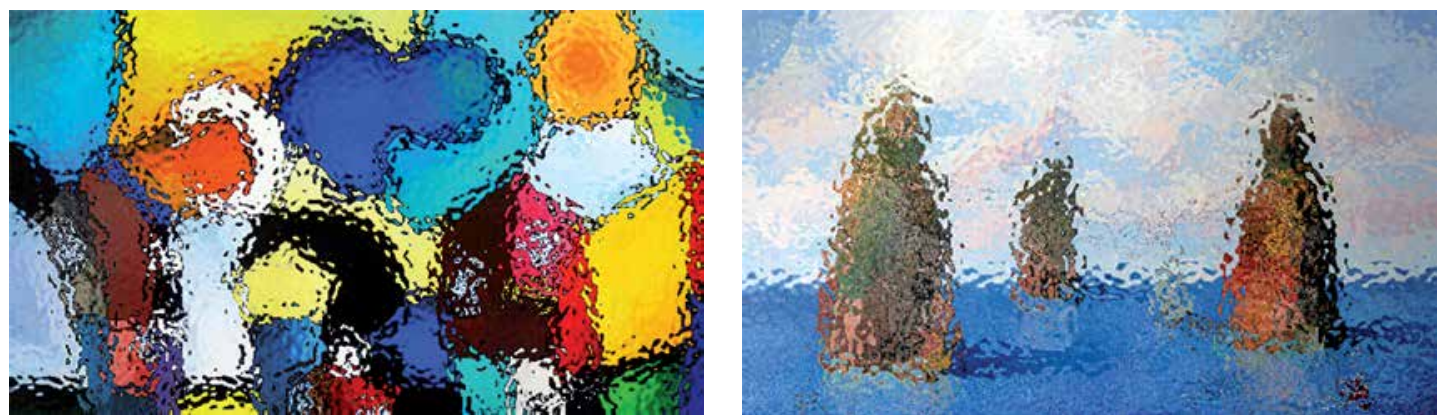

Fig. 1. Example of experimental presentation (figurative image on the left, abstract image on the right) in the decision task The images have been degraded for copyright reasons. 
An HP Intel Core 2 T5500 (1.66 GHz@1.66 GHz; 0.99 RAM GB and Mobile Intel 945 Express Chipset Family screen adapter) was used to present stimuli and record participants' responses. The images were projected on the screen by means of the OpenSesame program (Mathôt et al. 2012).

\section{Research design}

The experiment carried out followed an experimental, decision task paradigm. In every trial, the images could be abstract or figurative and they could appear on the left side of the screen or on the right one. Therefore, the design was $2 \times 2$ (Image-art style $\times$ Images-position) with the four experimental conditions of: (a) leftabstract, (b) left-figurative, (c) right-abstract, and (d) right-figurative. In this sense, since the images were paired, the experimental condition left-abstract (a) was equivalent to the right figurative one (d) and the condition of left-figurative (b) was equal to the right-abstract one (c).

\section{Data analysis}

The total number of data rows was 2,790 (90 trials $\times 31$ participants). The count of every preference of each participant in the decision task was made. Furthermore, RTs in deciding which art style participants preferred were also analyzed. The normality of the data distribution for every dependent variables (i.e., preference and RTs) was tested using the Kolmogorov-Smirnov (K-S) test of goodness of fit. Once the statistical assumption was checked, a repeated $2 \times 2$ ANOVA was conducted for the preference and for RT measures.

\section{Results}

\section{Preference}

For the count of the preferences for each participant, there was no statistically significant difference between its distribution and a normal distribution, $Z(31)=0.13, p=0.2$. A $2 \times 2$ ANOVA test was applied to calculate the main effects and the interaction effect. In this manner, a position effect was found, $F(1,30)=6.76$, $p<0.015$. The abstract images appeared 1,436 times on the left side of the screen and only 1,354 on the right side. There is no manipulation in this sense, the randomness did not work effectively and the program significantly presented a greater number of times the abstract images on the left.

With regards to the preference between abstract art and figurative art, there is a significant effect, $F(1,30)=10.44, p<0.004$, of higher preference for the figurative images (1,787 times) than for the abstract ones (1,003 times; see Fig. 2). It could be thought that this statistical difference could be caused by the significantly greater amount of abstract images presented on the left side of the visual hemifield (which would be processed theoretically by the right hemisphere, the "rational one"). Nevertheless, there is a difference of only $82(1,436-1,354)$ times between the presentation on the left and on the right of the screen while there is a difference of $784(1,787-1,003)$ between the times participants chose figurative images over abstract ones.

Finally, there is no interaction effect between the preference for a specific style depending on the side of the screen on which images were presented, $F(1,30)=0.04, p>0.250$. This result means that there is no kind of laterality effect, at least with the kind of image presentation we carried out.

\section{Response times}

For the mean RTs for each participant in deciding their preference, there was no significant difference either between its distribution and a normal distribution, $Z(31)=0.13$, $p=0.2$. In this analysis, two participants had to be excluded since they did not prefer in some conditions the abstract art pictures. Given that they did not prefer them, it was impossible to calculate how long it took for them to prefer abstract images over figurative images.

With regards to the presentation of images on both sides of the screen, there is no effect in the RTs for presentation in which the abstract art picture appeared on the left side and the figurative one on the right side compared to the ones in which the abstract image was presented on the right, $F(1,28)=0.32, p>0.250$.

Nevertheless, there is an effect, $F(1,28)=$ $4.28, p<0.049$, of the RT that participants take

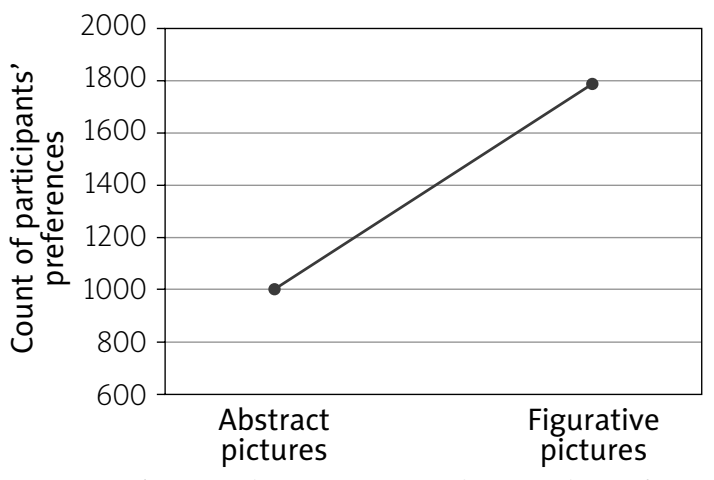

Fig. 2. Total count of participants' preferences for each Art style 


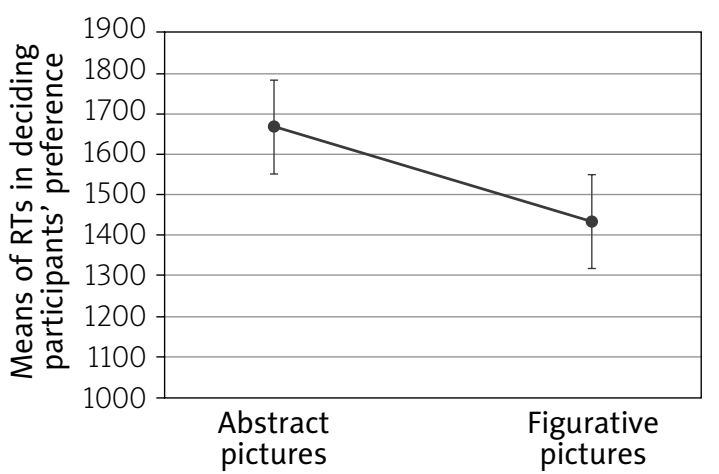

Fig. 3. Means of response times (RTs) in the decision of the preference of each Art style

to decide that they prefer the figurative images over the abstract ones (see Fig. 3). In this sense, as a mean, when participants decided they preferred the abstract art pictures, they took longer RT doing so $(\mathrm{M}=1,666.33 \mathrm{~ms}, \mathrm{SD}=123.67 \mathrm{~ms})$ than when they decided they preferred the figurative art pictures $(M=1,434.55 \mathrm{~ms}$, $\mathrm{SD}=115.45 \mathrm{~ms})$. The difference between the means of RTs is $231.78 \mathrm{~ms}$.

Finally, there is no interaction effect between the two previous variables, which accords with the conception that there is an effect of laterality when analyzing (paying attention) and making decisions about artworks.

\section{Conclusions}

First of all, neither for the count of preferences nor for the RTs is there an interaction effect. In this sense, there is no significant difference in the number of preferences (for abstract or figurative images) between when the abstract art was presented on the left side of the screen compared to when it was presented on the right. The exactly same case was for the figurative art (as it is symmetrical to the abstract art presentation). This result means that there is no effect of laterality. This finding accords with our main hypothesis; since the ACC is bilaterally active when the participants have to pay attention and make decisions (Bush et al. 2000), there would have been no laterality effect. Regarding the no-interaction and no-laterality effect in the kind of art preferences, we found that there is no interaction effect in RTs either, which also supports the idea that, for the decision making, there is no significant difference depending on the visual hemifield in which the elements of this decision task are presented. No contributions can be made about the perception or evaluation of art from the experimental setting we used (our findings are beyond the plain perception and evaluation of art).

Secondly, understanding art as a configuration of collective variables (Berlyne 1966) and taking into account that Psychology students are more analytical than Fine Art students (Hernández Belver 1990), our second hypothesis is also corroborated. In this sense, given the innate generative grammar (Chomsky 1980) of humankind, the fact that the figurative art does represent recognizable scenes or objects (Read 1948) and the fact that Psychology students are more analytical (Hernández Belver 1990), we found that these participants prefer the figurative images (since its collative variables are easier to analyze; Berlyne 1966) to the abstract ones (see Fig. 2). Future research will be designed to test whether there is the same effect with Fine Art students.

Thirdly, in regards to the previous point, since abstract art does not represent recognizable scenes or objects (Read 1948) and there is greater difficulty in the comparison between the collective variables in abstract art (Berlyne 1966) to their unknown model of reference, we found that the RTs are longer for abstract art than for figurative art in the preference/decision task (see Fig. 3). In this sense, it highlights the quantification that can be made in the process of trying to extract the meaning in abstract art. Therefore, we can affirm that, as a mean, participants spend $231.78 \mathrm{~ms}$ in trying to extract (we are not stating they actually get it) the meaning of abstract art to make the decision of their preference.

To the best of our knowledge, this is the first study that makes clear and quantifies how the cognitive system searches for meaning. The innate generative grammar (Chomsky 1980) makes human beings try to understand the world that surrounds us. This is not always possible, such as with abstract art that requires a set of previous experiences (in the form of a priori synthesis; Kant 1787/1948) to be completely analyzed. But this fact does not mean that the cognitive processes are not activated to accomplish this task anyway.

\section{References}

1. Berlyne DE. Uncertainty and conflict: A point of contact between information-theory and behavior-theory concepts. Psychol Rev 1957; 64: 329-339.

2. Berlyne DE. Conflict, arousal, and curiosity. McGraw Hill, New York 1960.

3. Berlyne DE. Arousal and reinforcement. In: D. Levine (Ed.). Nebraska symposium on motivation. University of $\mathrm{Ne}$ braska Press, Nebraska 1966. 
4. Berlyne DE. Aesthetics and psychobiology. Appleton-Century-Crofts, New York 1971.

5. Bush G, Luu P, Posner MI. Cognitive and emotional influences in anterior cingulate gyrus. Trends Cognit Sci 2000; 4: 215-222.

6. Chomsky N. On cognitive structures and their development: a reply to Piaget. In: Piatelli-Palmarini M (Ed.) Language and learning: the debate between Jean Piaget and Noam Chomsky. Havard University Press, Cambridge 1980.

7. Damasio A. Descartes' error: Emotion, reason, and the human brain. Avon Books, New York 1994.

8. Davidson RJ. Anterior cerebral asymmetry and the nature of emotion. Brain Cogn 1992; 20: 125-151.

9. Delgado JM. Mi cerebro y yo [My brain and me]. Temas de hoy, Madrid, Spain 1994.

10. Dickie G. El círculo del Arte: Una teoría del Arte [The circle of Art: A theory of Art]. Paidos Iberica, Madrid, Spain 2005.

11. Eder AB, Rothermund K, De Houwer J, et al. Directive and incentive functions of affective action consequences: an ideomotor approach. Psychol Res 2014; 79: 630-649.

12. Goddard C, Wierzbicka A. Semantic and lexical universals: theory and empirical findings. Netherland: John Benjamins, Amsterdam 1994.

13. Hegel G. Introducción a la estética [Introduction to aesthetic]. España: Península, Barcelona 1997.

14. Heilman KM. The neurobiology of emotional experience. J Neuropsychol Clin Neurosci 1997; 9: 439-448.

15. Hernández Belver M. La experiencia artística y el lado derecho del cerebro [The artistic experience and the right side of the brain]. Arte, Individuo Sociedad 1990; 3: 99 110. Available from: http://revistas.ucm.es/index.php/ ARIS/article/download/ARIS9090110099A/6044.

16. Kant I. Crítica de la Razón Pura [Critique of Practical Reason]. Fischer K (Ed. \& trad.). Argentina: Editorial Sopena Argentina, Buenos Aires 1948 (original work published in 1787).

17. Katz D. Psicología de la forma [Psychology of form]. España: Espasa Calpe, Madrid 1967.

18. Levy J. Cerebral asymmetries as manifested in split-brain man, in hemispheric disconnection and cerebral function. In: M. Kinsbourne, W.L. Smith (Eds.). Hemispheric disconnection and cerebral function. IL: Thomas, C. C., Springfield 1974.

19. Luria A. Human brain and psychological processes. Harper \& Row, New York 1966

20. Martinez E, Segura R, Sanchez L. El complejo mundo de la interactividad: emociones y redes [The complex of a interconnected world: Emotions and social media]. Revista Mediterránea de Comunicación 2011; 2: 189-208.

21. Mathôt S, Schreij D, Theeuwes J. Open sesame: an opensource, graphical experiment builder for the social sciences. Behav Res Methods 2012; 44: 314-324.

22. Moles A. Information theory and esthetic perception. J. E. Cohen (trans.). University of Illinois Press, Urbana 1966.

23. Panksepp J. Affective neuroscience. Oxford University Press, Oxford 1998.

24. Peretz I, Zatorre RJ. Brain organization for music processing. Annu Rev Psychol 2005; 56: 89-114.

25. Peretz I, Gagnon L, Bouchard B. Music and emotion: perceptual determinants, immediacy, and isolation after brain damage. Cognition 1998; 68: 111-141.

26. Read H. Art now: an introduction to the theory of modern painting and sculpture. Faber and Faber, London 1948.

27. Schmidt LA, Trainor LJ. Frontal brain electrical activity (EEG) distinguishes valence and intensity of musical emotions. Cognit Emotion 2001; 15: 487-500.
28. Tiso A. Arte y cognición: una experiencia con el lenguaje logo [Art and cognition: an experience with the logo language]. Arte Individuo Sociedad 1990; 3: 215-224. Available from: http://revistas.ucm.es/index.php/ARIS/ article/view/ARIS9090110215A/6057.

29. Vilchez JL. Mental footnotes: Knowledge constructivism from logical thinking to personal beliefs and therapy. Res Psychother Psychopathol Process Outcom 2016; 19 : 158-165.

30. Vilchez JL. Mental footnotes. Knowledge constructivism: from logical thinking and personal beliefs to social rationality and spiritual freedom. J Rel Health 2018; 57: 23432361.

31. Vilchez JL. Mental footnotes: Knowledge constructivism from logical thinking to daily functioning. Rev Contemp Philos 2019; 18: 7-22. 